\title{
SUBCRITICAL CRACK GROWTH INDUCED BY STRESS CORROSION IN HARDENED CEMENT PASTE
}

\author{
WEIJIN WANG ${ }^{*}$ TENG TONG ${ }^{\dagger}$ AND QIANG YU ${ }^{\dagger+}$ \\ 'University of Pittsburgh \\ Pittsburgh, PA USA \\ e-mail: wew41@pitt.edu \\ ${ }^{\dagger}$ University of Pittsburgh \\ Pittsburgh, PA USA \\ e-mail: tet16@pitt.edu \\ ${ }^{\dagger \dagger}$ University of Pittsburgh \\ Pittsburgh, PA USA \\ e-mail: qiy15@pitt.edu
}

Key words:Stress Corrosion, Subcritical Crack Growth, Deterioration, Cementitious Materials

\begin{abstract}
For concrete structures a primary driver of deterioration shortening their lifespans is the damage growth resulting from coupled chemo-mechanical attack. Under sustained service load coupled with corrosion, stress corrosion cracking will happen and lead to subcritical crack growth (SCG) in concrete members. In this study, the kinetics of crack growth in cement paste under concurrent mechanical and chemical attacks will be investigated experimentally. To obtain the complete crack velocity versus stress intensity factor $(K-v)$ curve, tests will be designed for experimental characterization to track the subcritical crack growth. In the test the specimens, which are immersed in a corrosive solution of high concentration, will be subject to sustained loading. To record the crack propagation as well as strain/stress distribution around crack tip, a high-resolution microscopic system and a non-contact digital image correlation (DIC) system will be used to scan the specimen surface. The recorded $(K-v)$ curves show that the proposed specimens, which are of a negative geometry, are capable of capturing the subcritical crack growth by using load control, and thus provide a novel alternative for characterizing the stress corrosion cracking in cementitious materials.
\end{abstract}

\section{INTRODUCTION}

Deterioration in concrete can be caused by many physical and chemical processes, which include creep and shrinkage, carbonation, calcium leaching, acid attack, free-thaw damage, weathering process and etc. Sustained loading can cause static fatigue and lead to the deterioration of concrete, even when the applied load is far less than the static strength of concrete. If coupled with corrosion, the static fatigue will turn into stress corrosion, which will lead to the subcritical crack growth (SCG) in concrete members under a further lower load. The growth of the subcritical cracks will degrade the concrete and when the crack length reaches certain critical values, the concrete integrity will be severely impaired.

SCG has been extensively investigated [114, 16-19] by recording the complete crack velocity versus stress intensity factor $(K-v)$ curves. Among these studies, double-torsion (DT) test is popularly used. Since the stress intensity factor $K$ is proportional to the 
external load $P$ but independent of the crack length $a$ in the DT test, a complete $K-v$ curve cannot be attained by using constant loading. To overcome this problem, a constant displacement is applied on the DT specimen to take advantage of the stress relaxation, which leads to varied load $P$ and crack velocity. To achieve constant displacement and monitor the associated stress relaxation, sophisticated equipment (e.g., high-accuracy LVDT, load cell, and controller) is needed in the DT test to control the displacement as well as to record the force change during crack propagation [4].

Due to the heterogeneity and age sensitivity of concrete, it is essential to test multiple similar specimens from the same batch concurrently to capture the subcritical crack growth and its associated scatter. This imposes a great financial burden on the DT tests because a number of LVDTs, load cells and controllers are needed. Another challenge in the DT test is the inelastic displacement caused by creep and shrinkage, which must be identified when one calculates $K$ based on the recorded force history $P(t)$.

To overcome these obstacles, this study is aimed at finding an alternative, which is capable of capturing subcritical crack growth by using load control. Thus, the sophisticated displacement-control test equipment in the DT test is no longer needed. Here a comprehensive investigation of the SCG is carried out for the hardened cement paste specimens under both sustained loading and calcium leaching condition.

\section{DESIGN OF A NOVEL TEST}

\subsection{Design of Specimen}

To use load control, a novel test based on the concept of negative geometry will be proposed. In linear elastic fracture mechanics (LEFM), a crack subject to increasing force can propagate stably only in specimens of negative geometry (i.e., $K$ decreases with crack length $a$ ). This means if specimens of negative geometry are used, complete $K-v$ curves may be attained under a constant load.

In view of this, a trapezoid plate shown in
Fig. 1a is investigated [15]. An empirical formula to calculate the Mode I stress intensity factor at the crack tip of this $2 \mathrm{D}$ specimen is given in Eq. 1, where $m, d, h$ and $h_{a}$ are shown in Fig. 1, and $f(m)$ is the geometry correction factor.
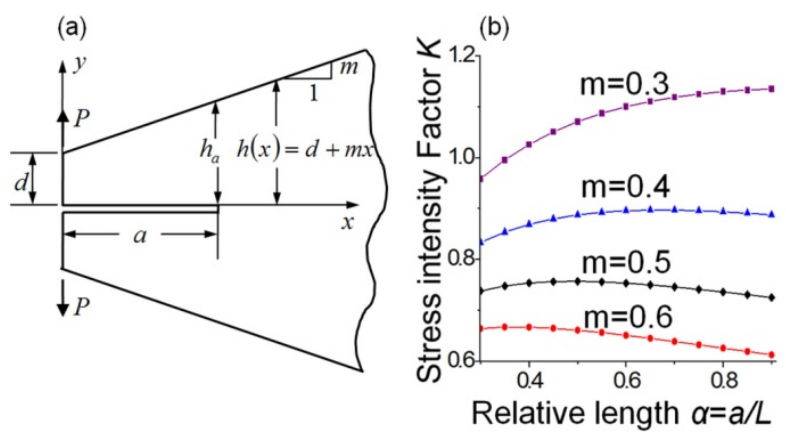

Figure 1: (a) Illustration of the trapezoid specimen [15]; and (b) the relationship between stress intensity factor and relative crack length for different slopes $m$.

$$
\begin{gathered}
K_{I}=\frac{P}{\sqrt{h_{a}}} \cdot f(m) \cdot\left(\frac{a}{h_{a}}+0.7\right) \\
h_{a}=h(a)=d+m a \\
f(m)=3.46-2.65 m+1.89 m^{\frac{3}{2}}
\end{gathered}
$$

Based on Eq. 1, the relationship between $K_{I}$ and relative crack length $\alpha=a / L$ ( $L$ is the total length of specimen in $x$ direction) for specimens of different slopes $m$ are shown in Figure 1b. When the slope $m$ is equal or larger than 0.5, the stress intensity factor $K_{I}$ decreases with crack length $a$ after $\alpha$ reaches 0.4. This implies the trapezoidal plate turns to negative geometry. Thus, stable crack propagation under a constant load can be achieved in specimens with slopes $m$ greater than 0.5 by adjusting the initial notch length. In this study, a trapezoidal specimen of $m=$ $0.6, d=20 \mathrm{~mm}$, and $L=100 \mathrm{~mm}$ is selected (Fig. 2) and the dependence of $K_{I}$ on crack length is calculated in ABAQUS based on the boundary conditions used in test. 


\subsection{Material and specimen preparation}

In order to eliminate the disturbance induced by the interfaces between coarse aggregates and cement paste, pure cement paste is used in this experiment to cast the trapezoid specimens. Two water-cement ratios, namely 0.35 and 0.40 , are used in two mix designs respectively. For each mix design, 9 trapezoidal plates and 2 standard cylinders will be cast. A guiding groove is prefabricated in the middle of the plate and the subcritical crack is expected to grow along it.

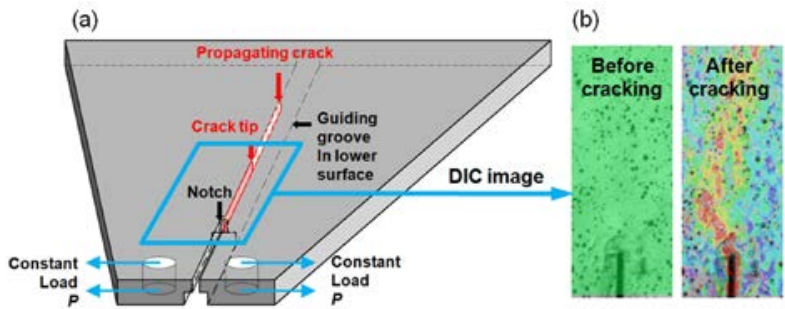

Figure 2: (a) Schematic illustration of the specimen used in the test; (b) DIC images.

\subsection{Testing under Constant Load}

The mechanical properties of each mix are shown in Table 1. To eliminate the effect of shrinkage, all the specimens will be immersed in water. The constant load is applied by hanging equal-weight steel blocks on both sides of the notch (Fig. 3).

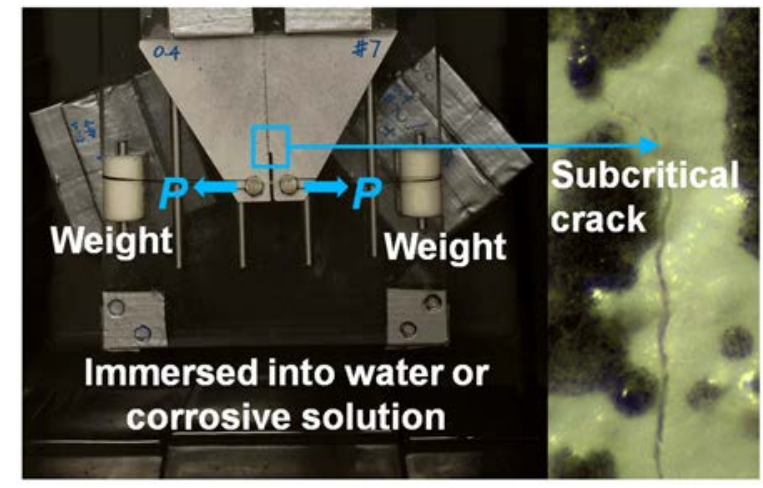

Figure 3: Top view of the loading configuration and the detection of crack tip through a high-resolution microscopic system.

Among the 9 specimens of each batch, 6 plates are immersed in an ammonium nitrate solution $\left(\mathrm{NH}_{4} \mathrm{NO}_{3}\right)$ of $10 \%$ concentration, which will accelerate the calcium leaching process; while the remaining 3 plates are loaded in water to service as a control group of static fatigue. For specimens in the $\mathrm{NH}_{4} \mathrm{NO}_{3}$ solution, their surface is painted with an anticorrosion epoxy. Thus, the corrosive agents can only penetrate into the specimens through the crack surface. The selected loads for each group are given in Table 2 .

During test, the location of crack tip is determined through a high-resolution microscopic system. The crack velocity can be expressed as an averaged value based on the length difference between two subsequent measurements and the duration.

Table 1: Material properties

\begin{tabular}{cccc}
\hline \multirow{2}{*}{ Parameters } & \multicolumn{2}{c}{ Water-cement ratio } \\
\cline { 2 - 4 } $\begin{array}{c}\text { Compressive } \\
\text { strength }\end{array}$ & $f_{c}^{\prime}$ & $45.13 \mathrm{MPa}$ & $45.00 \mathrm{MPa}$ \\
\hline $\begin{array}{c}\text { Young's } \\
\text { modulus }\end{array}$ & $E$ & $23.00 \mathrm{GPa}$ & $17.80 \mathrm{GPa}$ \\
\hline Poisson's ratio & $v$ & 0.29 & 0.26 \\
\hline
\end{tabular}

Table 2: Constant load applied to the specimen

\begin{tabular}{ccc}
\hline & \multicolumn{2}{c}{ Water-cement ratio } \\
\cline { 2 - 3 } & 0.35 & 0.40 \\
\hline $\begin{array}{c}\text { Corrosion group } \\
\text { (in } \mathrm{NH}_{4} \mathrm{NO}_{3} \text { solution) }\end{array}$ & $26.8 \mathrm{~N}$ & $26.5 \mathrm{~N}$ \\
\hline $\begin{array}{c}\text { Control group } \\
\text { (in water) }\end{array}$ & $35.8 \mathrm{~N}$ & $35.4 \mathrm{~N}$ \\
\hline
\end{tabular}

\section{TEST RESULTS}

A total of 12 trapezoid specimens from two batches of cement paste (6 from each batch) were subjected to the stress corrosion test simultaneously; while 6 plates are under static fatigue in water. The subcritical crack growth in each specimen is tracked and corresponding $K-v$ curve is obtained. Fig. 4 shows the $K-v$ curves obtained in specimens loaded in water.

In log-log scale, the $K-v$ curves are almost straight lines for the plates under static fatigue. For specimens of $w / c=0.35$, they display a steeper slope than those of $w / c=0.40$. This indicates that the threshold stress intensity factor $K_{0}$ for static fatigue decrease with the increase of water-cement ratio. 
For specimens loaded in $\mathrm{NH}_{4} \mathrm{NO}_{3}$ solution, three distinctive regions (I, II and III) appear in their $K-v$ curves due to the chemomechanical coupling (Fig. 5). In region III, the $K-v$ curve shows a slope steeper than those of region II and region I for both water-cement ratios. In region II, the slope of the $K-v$ curve is almost flat, which indicates that crack velocity is almost independent of the stress intensity factor $K_{I}$. Thus, in this region, the crack velocity is mainly affected by the transport of reactive species from surrounding environment to the crack tip. In region I, the slope of $K-v$ curve becomes stepper again, but is less than that of region III. This means in this region, crack propagation is controlled by both the environment assisted deterioration and the mechanical behavior of material.
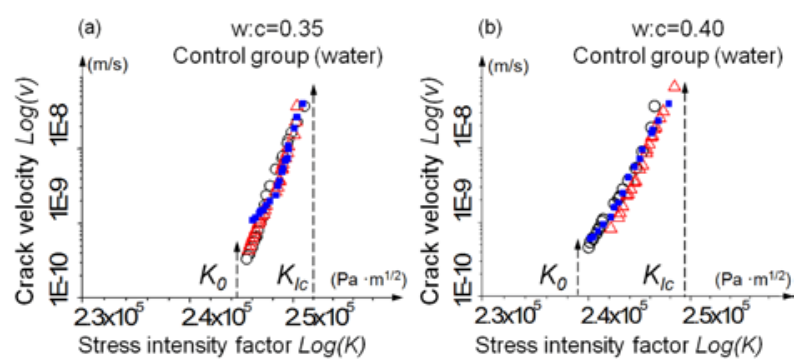

Figure 4: $K-v$ curves in log-log scale of control groups for water-cement ratios of 0.35 and 0.40 .
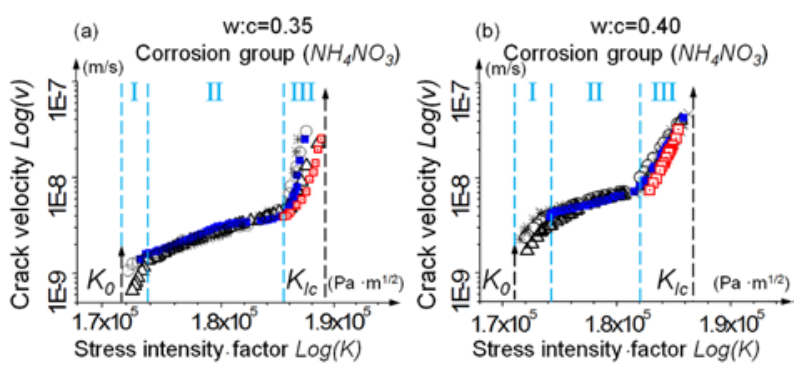

Figure 5: $K-v$ curves in log-log scale of corrosion groups for water-cement ratios of 0.35 and 0.40 .

Based on the results of the $K-v$ curves obtained in the test, the values of the critical fracture toughness $K_{I c}$ and the threshold stress intensity factor $K_{0}$ can be predicted. It is found that with the increase of water-cement ratio, both $K_{I c}$ and $K_{0}$ decrease (Table 3 ).
Table 3: Obtained values of $K_{0}$ and $K_{I c}$

\begin{tabular}{ccccc}
\hline & \multicolumn{4}{c}{ Water-cement ratio } \\
\cline { 2 - 5 } & 0.35 & 0.35 & 0.40 & 0.40 \\
\cline { 2 - 5 } & $K_{0}$ & $K_{I c}$ & $K_{0}$ & $K_{I c}$ \\
\hline Unit & \multicolumn{1}{c}{$\left(\times 10^{5} \mathrm{~Pa} \cdot \mathrm{m}^{-1 / 2}\right)$} \\
\hline $\begin{array}{c}\text { Corrosion } \\
\text { group }\end{array}$ & 1.72 & 1.89 & 1.71 & 1.86 \\
\hline $\begin{array}{c}\text { Control } \\
\text { group }\end{array}$ & 2.45 & 2.52 & 2.39 & 2.50 \\
\hline
\end{tabular}

To correlate the crack tip identified by the microscope system on the specimen surface with the crack propagation beneath concrete surface, two specimens with different crack length are scanned by a 3D CT-scan system. The resolution of the CT-scan system is up to $11.62 \mu \mathrm{m}$, sufficient for identifying mesocracks in the cement paste. Comparing the crack tips found by the 3D CT-scan with the ones obtained by the high-resolution microscope system, the difference is negligible, only about $1.13 \%$ and $0.27 \%$ of the crack length, respectively. Thus, the accuracy of crack tip detection is confirmed.

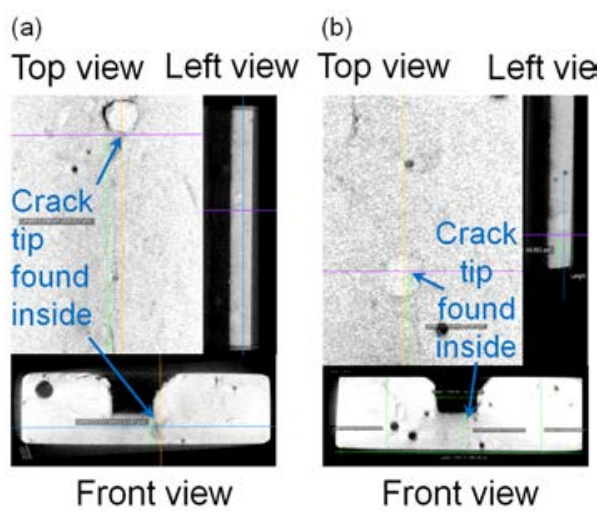

Figure 6: Three view layout from CT-scan result for different crack lengths

\subsection{Degree of corrosion}

The $\mathrm{pH}$ value of cement paste is about 13 . For specimens attacked by $\mathrm{NH}_{4} \mathrm{NO}_{3}$ solution, calcium leaching is accelerated and the cement paste around the crack tip is weakened. The degree of corrosion in the specimens is assessed using a solution of phenolphthalein indicator that appears colorless at $\mathrm{pH}$ levels lower than 9 and magenta in contact with alkaline cement paste with $\mathrm{pH}$ values greater 
than 9.

The phenolphthalein test to examine the degree of corrosion is carried out on stages when the slope of the $K-v$ curve starts to change from one region to another (Fig. 7). For instance, stage 1 occurs at the end of region III and the beginning of region II. At this stage, one specimen from each corrosion group is sacrificed. The Corroded area appears colorless while non-affected area shows magenta. By measuring the length of corroded area at different stages on each specimen, the degree of corrosion can be quantitatively evaluated.

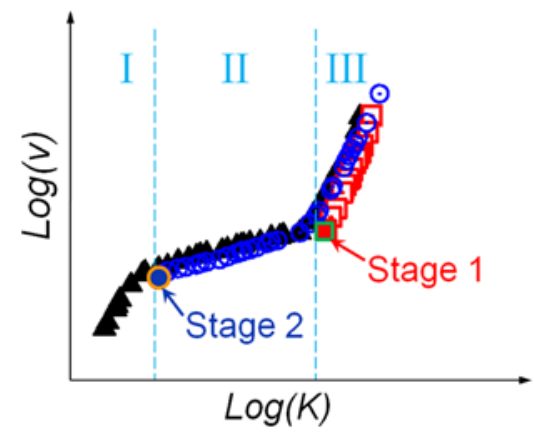

Figure 7: Schematic illustration of stages to conduct phenolphthalein tests

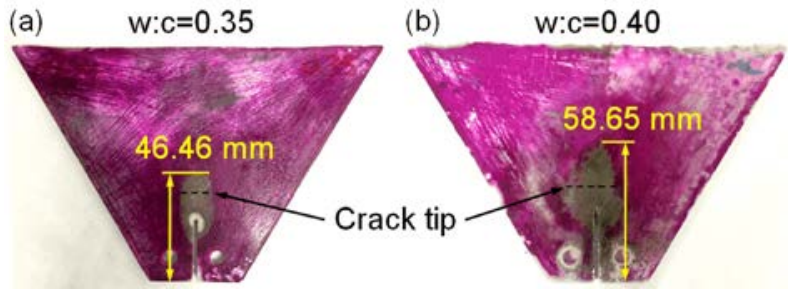

Figure 8: Degree of corrosion in stage 1 from phenolphthalein test

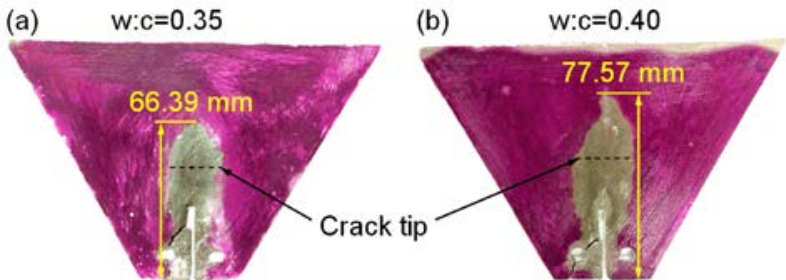

Figure 9: Degree of corrosion in stage 2 from phenolphthalein test

\section{CONCLUSIONS AND FUTURE PERSPECTIVES}

A novel test is designed to investigate SCG in cement paste specimen under coupled chemo-mechanical attack. This method has a significant advantage of obtaining real-time values of the stress intensity factor and the crack velocity through constant loading. Complete $K-v$ curves are obtained in the tests. Compared with the popular DT test, this method uses simple loading instruments and can test several specimens from the same batch of cement paste simultaneously. The significant differences of $K-v$ curves from different groups are captured: an oblique line for static fatigue and three distinctive regions for stress corrosion, which indicate the coupled influences of chemical and mechanical effect.

\section{REFERENCES}

[1] Atkinson, B. K. 1982. Subcritical crack propagation in rocks: theory, experimental results and applications. Journal of Structural Geology; 4(1), pp.41-56.

[2] Atkinson, B. K. 1984. Subcritical crack growth in geological materials. Journal of Geophysical Research: Solid Earth; 89(B6), pp.4077-4114.

[3] Beaudoin, J.J. 1985. Effect of humidity on subcritical crack growth in cement paste. Cement and Concrete Research; 15(5), pp.871-878.

[4] Cai, W. 2012. Subcritical crack growth in hardened cement paste (Doctoral dissertation, Diss., Eidgenössische Technische Hochschule ETH Zürich, Nr. 20611, 2012).

[5] Evans, A.G., 1972. A method for evaluating the time-dependent failure characteristics of brittle materials - and its application to polycrystalline alumina. Journal of Materials Science; 7(10), pp.1137-1146.

[6] Evans, A.G. and Williams, D.P., 1973. A simple method for studying slow crack growth. Journal of Testing and Evaluation;1(4), pp.264-270. 
[7] Evans, A.G., Clifton, J.R. and Anderson, E., 1976. The fracture mechanics of mortars. Cement and Concrete Research; 6(4), pp.535-547.

[8] Freiman, S.W., Mulville, D.R. and Mast, P.W., 1973. Crack propagation studies in brittle materials. Journal of Materials Science; 8(11), pp.1527-1533.

[9] Fuller, E.R., 1979. An evaluation of double-torsion testing-analysis. In Fracture mechanics applied to brittle materials. ASTM International.

[10] Janssen, C., 1977. Specimen for fracture mechanics studies on glass. Revue de Physique Appliquée; 12(5), pp.803-803.

[11] Mindess, S., Nadeau, J.S. and Hay, J.M., 1974. Effects of different curing conditions on slow crack growth in cement paste. Cement and Concrete Research; 4(6), pp.953-965.

[12] Pletka, B.J., Fuller, E.R. and Koepke, B.G., 1979. An evaluation of doubletorsion testing-experimental. In Fracture mechanics applied to brittle materials. ASTM International.

[13] Shyam, A. and Lara-Curzio, E., 2006. The double-torsion testing technique for determination of fracture toughness and slow crack growth behavior of materials: a review. Journal of materials science; 41(13), pp.4093-4104.

[14] Swanson, P.L., 1984. Subcritical crack growth and other time and environment dependent behavior in crustal rocks. Journal of Geophysical Research: Solid Earth; 89(B6), pp.4137-4152.

[15] Tada, H.I.R.O.S.H.I., Paris, P.C. and Irwin, G.R., 2000. The analysis of cracks handbook. New York: ASME Press; 2, p.1.

[16] Wecharatana, M. and Shah, S.P., 1980. Double torsion tests for studying slow crack growth of Portland cement mortar. Cement and Concrete Research; 10(6), pp.833-844.

[17] Wiederhorn, S.M., 1967. Influence of Water Vapor on Crack Propagation in Soda- Lime Glass. Journal of the American Ceramic Society; 50(8), pp.407414.

[18] Wiederhorn, S.M., 1968. Moisture assisted crack growth in ceramics. International Journal of Fracture Mechanics; 4(2), pp.171-177.

[19] Wiederhorn, S.M., Freiman, S.W., Fuller Jr, E.R. and Simmons, C.J., 1982. Effects of water and other dielectrics on crack growth. Journal of Materials Science; 17(12), pp.3460-3478. 